\title{
Characterization of pure and silver exchanged natural zeolite filled polypropylene composite films
}

\author{
H. Pehlivan, D. Balköse, S. Ülkü, F. Tihminlioğlu * \\ Department of Chemical Engineering, Faculty of Engineering, İzmir Institute of Technology, Gülbahçe, 35430 Urlalİzmir, Turkey
}

Received 29 December 2003; received in revised form 6 April 2005; accepted 17 April 2005

Available online 8 June 2005

\begin{abstract}
In the present study, untreated and silver exchanged natural zeolite-polypropylene (PP) composites were prepared and characterized by means of different techniques (TGA, DSC, mechanical tests, density measurements, optical microscopy and colorometer). The effects of zeolite loading and silver concentration on the composite properties were investigated. The thermal characterization studies showed that the addition of the zeolite increased the crystallinity of the composites acting as a nucleating agent in PP crystallization and retarded the degradation of PP. At low silver concentrations, the zeolite behaved as a decelerating agent in PP degradation, however at higher silver concentrations, the composites degraded at a faster rate than pure PP. The experimental densities of the composites were found to be lower than the theoretical densities. When the tensile tested samples are considered, the densities were even lower indicating porous structure of the films. From the optical micrographs of the tensile tested films, it was clearly seen that the stretching along the machine direction caused hole formation around the particles. The optimum conditions obtained in this study for the PP-silver zeolite composite film production are in the range of $2-4 \mathrm{wt} \%$ zeolite treated with $4.36 \mathrm{mg} \mathrm{Ag}^{+} / \mathrm{g}$ zeolite. At higher zeolite loadings, the film becomes brittle and at higher $\mathrm{Ag}^{+}$concentrations, the film produced was discolored.
\end{abstract}

(C) 2005 Elsevier Ltd. All rights reserved.

Keywords: A. Particle reinforced polymer composites; B. Mechanical properties; D. TGA, DSC; E. Extrusion

\section{Introduction}

Particulate filled polypropylene composites are used extensively in various application fields such as; food packaging, medical delivery systems, carpets, fibers, protective coating, automobile, electrical and furniture industries. Because of their importance, these composite systems have been investigated to meet the increasing requirements of these fields and to produce tailor made properties for special applications. One way of tailoring the properties of PP is to add the appropriate particulate filler into the matrix. Talc, calcium carbonate, mica, sil-

\footnotetext{
* Corresponding author. Tel.: +90232750 6651; fax: +90232750 6645.

E-mail address: fundatihminlioglu@iyte.edu.tr (F. Tihminlioǧlu).
}

ver and clays are the most commonly used ones as a filler in the PP matrix [1-4]. Recently, different types of zeolite minerals, either natural (clinoptilolite, mordenite, chabazite), or synthetic (A-type, X-type, Y-type), are being employed as particulate fillers into the polymer matrix $[5,6]$.

It has been established that zeolites are suitable for removing $\mathrm{Ag}$ ions from silver containing solutions and that silver zeolites are increasingly investigated as germicidal, bactericidal, antifungal, and antiseptic components in different compositions [7-9]. Since the growth of pathogenic microorganisms and their penetration into the body is the main problem, studies were being established for an antiseptic agent to prevent invasive infection. Klasen [9] has investigated the silver as a source of antiseptic agent. Silver salts appeared to meet 
the requirements to be considered as an antiseptic agent. The modification of inorganic compound by the addition of silver became attractive to protect the circumstances from the diseases originating from microorganisms. Ionic silver has the highest antibacterial activity among metal ions and a variety of silver compounds have been used as topically applied agents for treatment of burns and ocular infections [9] and as well as polymer additives in food packaging.

The original clinoptilolite, $\mathrm{NH}_{4}$-form, $\mathrm{K}$-form, and Na-form of clinoptilolite were determined to take 74.0, 84.3, 86.6, and $120.7 \mathrm{mg} \mathrm{Ag}^{+} / \mathrm{g}$ clinoptilolite, respectively. The good exchangeability of silver ions into zeolite can be explained by the high polarizability of silver ions. The electrostatic charge of zeolite lattice is capable of polarizing silver ions so that they become dipoles directing their positively charged end to the lattice [10].

Hagiwara et al. [7] studied zeolite particles retaining $\mathrm{Ag}$ ions having antibacterial properties. They proposed a polymeric substance holding the metallic ions to be used in various fields. In their proposal, a polymer contains organic functional groups having an ion-exchange function over a complex forming function and thereby these groups retain the metal ions. Since the zeolite is more cost effective compared to the other antimicrobial agents and no toxicity to humans is reported, they are used in many manufactured goods that have antibacterial coating/ingredients, such as toothbrushes, and toothpaste, bath and toilet tiles, kitchen utensils, baby toys and recently medical instruments, especially in Japan. Hagiwara et al.'s [7] invention provides two processes for producing polymer article. One process is characterized by admixing zeolite particles retaining at least one metal ion having a bactericidal property with an organic polymer or a mixture of polymers at any stage prior to moulding the organic polymer to form the shaped article. Another process is characterized in that an organic polymer or a mixture of polymers containing zeolite particles is moulded and then treated with an aqueous solution of at least one metal ion having a bactericidal property to provide at least part of the zeolite particles with so-called metal ion. Silver ions are taken up by microbial cells disrupting the cells's enzymatic activity. Commercial examples of the silver exchanged zeolites include Zeomic, Apacider, AgIon, Bactekiller and Novaron.

As reported in a variety of studies [7-9,11], silver zeolite exhibits excellent antibiotic property. However, such an antibiotic zeolite suffers from the disadvantage that it gradually discolors in time. While this discoloration has no effect on antibiotic effect, depending on the nature of the product containing this antibiotic zeolite, this feature may greatly reduce their commercial value.

Although an extensive amount of work has been done related with polypropylene based composite systems, most of the studies were conducted with calcium carbonate, talc, or mica and few studies were reported with zeolite as a filling material in polymer matrix. Özmıhçı et al. [6] previously investigated the preparation and characterization of natural zeolite-polypropylene composites proposing natural zeolite from Gördes region as an alternative filler to $\mathrm{CaCO}_{3}$. In the so-called study, PEG 4000 (Polyethylene Glycol) was selected as the surface modification material among different materials, which were calcium stearate, and stearic acid because in the case of PEG 4000, the agglomerates of the zeolite particles were broken into smaller particles to a higher extent than the other modification materials $[3,12]$.

In the present study, the preparation and characterization of untreated and silver exchanged zeolite filled polypropylene composite system were studied. The effects of zeolite addition to the polymer matrix and silver concentration on the thermal, mechanical, and structural properties of the composites were investigated. The optimum zeolite and silver concentration based on the thermal stability, mechanical strength and discoloring properties of the composites were determined.

\section{Experimental}

\subsection{Material}

Isotactic PP (MH-418, MFI $=4-6 \mathrm{~g} / 10 \mathrm{~min}$, PETKIM Co.) in pellet form with a density of $895 \mathrm{~kg} / \mathrm{m}^{3}$ was used for the matrix material and natural zeolite, clinoptilolite, from Gördes, Turkey, was used as filling material for the preparation of composites. For the surface modification of the zeolite, PEG 4000 (Aldrich) was used to prevent agglomerations and provide uniform distribution along the PP phase. The natural zeolite was characterized earlier by Akdeniz [13] and was used by Özmıç̧ı [14] to prepare zeolite-PP films.

\subsection{Preparation of the materials}

The natural zeolite rocks were first hammered to break down into smaller particles. These smaller particles were then wet-grinded using Multifix Ball-Mill with ethanol for $4 \mathrm{~h}$. After the grinding step, the slurry was dried at $110{ }^{\circ} \mathrm{C}$ for sufficient time to remove the ethyl alcohol from the mixture. The dried zeolites were then sieved from the $45 \mu \mathrm{m}$ sieve.

$\mathrm{AgNO}_{3}$ solutions with initial concentrations in the range of $5-5000 \mathrm{ppm}$ were used as the ion-exchange media. Zeolite minerals placed in $\mathrm{AgNO}_{3}$ solutions were kept at $25{ }^{\circ} \mathrm{C}$ for $24 \mathrm{~h}$ using a water bath equipped with a shaker and a top cover preventing the passage of light. At each set of experiment the solid to liquid ratio was kept constant as 1:100 (w/v). Following the ionexchange process, by filtration, the solid and the liquid 
part of the slurry was separated. The liquid phase was centrifuged for the removal of colloidal zeolite particles and was analyzed for the remaining silver ion concentration present in the solution. The solid phase was washed twice for the removal of excessive silver ions. The samples were then dried in a vacuum oven at 400 mbar and $110^{\circ} \mathrm{C}$ for $3 \mathrm{~h}$.

PEG 4000 was used for the surface modification of silver exchanged zeolites to provide uniform distribution of zeolites in the PP phase. Firstly, silver exchanged zeolites were mixed with $50 \mathrm{wt} \%$ aqueous ethanol solution containing $10 \mathrm{wt} \%$ PEG 4000 modifier. Then the mixture was dried in a vacuum oven at $110^{\circ} \mathrm{C}$ for $3 \mathrm{~h}$. Zeolite to solution ratio was taken as $1: 0.3$ on weight/ volume basis [14].

The extent of silver exchange onto the zeolites was determined by analyzing the remaining $\mathrm{Ag}^{+}$concentration in the liquid phase using Varian ICP-AES (inductively coupled plasma-atomic emission spectrometer). The amounts of $\mathrm{Ag}^{+}$loaded per gram of zeolite for initial $\mathrm{AgNO}_{3}$ concentrations of 50,500 , and $5000 \mathrm{ppm}$ were determined as $4.36,27.85$, and $183.78 \mathrm{mg}$, respectively.

The sorption isotherm of $\mathrm{Ag}^{+}$on zeolite was determined and compared with the Langmuir and Freundlich isotherm equations. The experimental data and the Freundlich isotherm solution showed a better agreement with each other compared to the Langmuir isotherm. The constants, $K$ and $n$, obtained from the Freundlich isotherm $\left(q=K C^{1 / n}\right)$ are 1.73, 2.08, respectively. Czaran et al. [10] have determined the silver uptake of the clinoptilolite depending on different monocationic forms of clinoptilolite (original, $\mathrm{K}-, \mathrm{NH}_{4}$, , or Na-form). The uptake was between 74 and $121 \mathrm{mg} \mathrm{Ag}^{+} / \mathrm{g}$ zeolite. The maximum amount of silver taken by Gördes 1 zeolite (183.78 $\mathrm{mg} \mathrm{Ag}^{+} / \mathrm{g}$ zeolite), in the present study, was comparable with the silver uptake in the different monocationic forms of the clinoptilolite.

\subsection{Composite preparation}

Zeolites treated with different amounts of $\mathrm{Ag}^{+}$(50, $500,5000 \mathrm{ppm}$ ) containing solutions were mixed with PP pellets by physical means. Due to the density difference between the PP and zeolite particles, the zeolites agglomerated at the bottom of the container. In order to prevent the agglomeration of particles dioctyl phthalate (DOP) was used as a plasticizer. PP pellets, $45 \mu \mathrm{m}$ zeolite particles $(2,4$, and $6 \mathrm{wt} \%)$, and DOP $(10 \%$ total $\mathrm{w} / \mathrm{v}$ ) were mixed. The zeolite dispersion in DOP coated the PP pellets evenly. And they were conditioned at $85^{\circ} \mathrm{C}$ at 400 mbar pressure using a vacuum pump to ensure the displacement of the air in the pores of the zeolite with DOP for an hour before the film drawing process. The mixture was then fed to the hopper of the mini extruder (Axon BX-18) for the extrusion process.
The zone temperatures in the extruder kept constant throughout the film drawing process were in between 200 and $220^{\circ} \mathrm{C}$ and the screw speed was $120 \mathrm{rpm}$. The extruder has an $L / D$ ratio of 20 , a diameter of $18 \mathrm{~mm}$, and a flat die of dimensions of $(50 \times 1 \mathrm{~mm})$. Axon two roll mill (AXON, 2R-180) with a roller speed of $90 \mathrm{rpm}$ was used to cast the film from the extruder. Tap water was circulated in polished rolls in order to solidify the polymer melt from the extruder. Thus the films having thickness around $275 \mu \mathrm{m}$ and width around $18 \mathrm{~mm}$ were obtained.

\subsection{Characterization and properties}

Thermal analyses of the untreated and silver exchanged zeolite containing PP films were conducted using Shimadzu differential scanning calorimeter (DSC, 50) and Shimadzu thermal gravimetric analyzer (TGA, 51). The experiments were carried out from room temperature up to $500{ }^{\circ} \mathrm{C}$ for the DSC analyses and up to $1000^{\circ} \mathrm{C}$ for the TGA analyses, at heating rates of 5 , 10 , and $20^{\circ} \mathrm{C} / \mathrm{min}$. The analyses were performed in a dry nitrogen atmosphere. $\mathrm{N}_{2}$ flow rate was $40 \mathrm{ml} / \mathrm{min}$ and kept constant through out the experiments.

Mechanical tests of the extruded composite films were performed on a Instron Machine (Series IX Automated Materials Testing System). The samples were tested according to ASTM 822 standard. The tensile tests of the films were carried at a crosshead speed of $500 \mathrm{~mm} / \mathrm{min}$, with a max. allowable load cell of $50 \mathrm{kgf}$. Each test was repeated three times and the mean values were used.

Optical micrographs of the samples with different zeolite loadings, and $\mathrm{Ag}^{+}$concentrations, and the tensile tested samples were taken using transmission optical microscope fitted with Olympus BX-60.

XRD experiments were carried out on a Philips Powder Diffraction instrument and the data were taken using Philips X'Pert software. $\mathrm{Cu} \mathrm{K} \alpha$ radiation with wavelength $0.154 \mathrm{~nm}$ was used. The degree of crystallinity was calculated as the ratio of total integral intensities of crystalline peaks $\left(I_{\mathrm{c}}\right)$ to the integral intensities of amorphous and crystalline peaks $\left(I_{\mathrm{a}}+I_{\mathrm{c}}\right)$.

Densities of the films, $12 \mathrm{~mm}$ in diameter, were measured with the density kit of Sartorius YDK 01 balance making use of the Archimedes' Principle. For the tensile tested samples, $1 \times 10 \mathrm{~cm}$ samples were used for density measurements. Both the sample weight and the weight of the water displaced by the sample were recorded.

To determine the discoloring effect of $\mathrm{Ag}$ ions on the composite films, the color of the composite films containing silver zeolite exposed to sunlight was measured by placing each sample on a white paper using Minolta color-color difference meter 2600D (using D 65 rays). The results are compared with respect to the reference sample, pure polypropylene film. 


\section{Results and discussion}

\subsection{Morphology of the films}

The microstructure of the composite materials without any treatment was examined by their transmitted optical micrographs. Fig. 1(a) shows the transmitted optical micrograph of tensile tested pure PP film. In the tensile tested samples, it is easier to see the orientation (alignment) of the PP molecules. Effect of zeolite addition to PP matrix was also examined. Fig. 1(b) shows the optical micrographs of the PP films containing $6 \mathrm{wt} \% \mathrm{Ag}$-zeolite ( $183.78 \mathrm{mg}$ silver/g zeolite). The agglomerates of the zeolite particles, which are the spherical dark particles, could easily be seen within the aligned PP matrix phase. Although the zeolite particles were ground down to $45 \mu \mathrm{m}$, due to the interface incompatibility between the matrix and the filler phases, very large agglomerates formed, leading a non-uniform zeolite distribution throughout the composite films. When same amount of zeolite loaded composite films were stretched, it was seen that void formation occurred, and voids grew around the zeolite particles as seen in Fig. 1(c). The brighter part represents the PP matrix and the dark part represents the zeolite particles. It was observed that the stretching along the machine direction can be detected as another layer, and air is entrapped around the zeolite particles.

\subsection{Film orientation during processing and tensile testing}

\subsubsection{Machine direction}

The polymer melt flowing from the flat die $(50 \mathrm{~mm} \times$ $1 \mathrm{~mm}$ ) is pulled at a higher speed by the calender to obtain the film having the size of $(18 \mathrm{~mm} \times 0.275 \mathrm{~mm})$. Since the maximum flow rate from the extruder and calender should be identical, the draw ratio of the films in machine can be calculated using the following equation:

Draw ratio $=\frac{\text { Cross }- \text { section of the die }}{\text { Cross }- \text { section of the calender }}$.
Thus, the PP film is drawn with a draw ratio of 10 in the machine direction during its production.

\subsubsection{Cold drawing of the film in tensile test machine}

The films were cold drawn during tensile testing. They were elongated 2-4 times of their original length before they were broken.

\subsection{Density measurements}

While stretching the films, in machine or transverse directions, pores form around the filler particles, causing a decrease in the density. The theoretical densities were determined using Eq. (2) to compare with the experimental results.

$d_{\mathrm{c}}=\frac{\sum M_{i}}{\sum\left(M_{i} / d_{i}\right)}=\left[\frac{\left(M_{1}+M_{2}+M_{3}\right)}{\left(M_{1} / d_{1}+M_{2} / d_{2}+M_{3} / d_{3}\right)}\right]$,

where $d_{c}$ is the theoretical composite density, $M$ is the mass, $d$ is the density, and 1,2 , and 3 denote zeolite, $\mathrm{PP}$, and DOP, respectively $\left(d_{\text {zeolite }}=1.8 \mathrm{~g} / \mathrm{cm}^{3}\right.$; $\left.d_{\mathrm{pp}}=0.89 \mathrm{~g} / \mathrm{cm}^{3} ; d_{\text {DOP }}=0.98 \mathrm{~g} / \mathrm{cm}^{3}\right)[15]$.

The void fractions in the composites were determined using Eq. (3). The experimental and the theoretical densities and the void fraction values for the samples are tabulated in Table 1.

$d_{\mathrm{c}, \mathrm{e}}=(1-\varepsilon) d_{\mathrm{c}, \mathrm{t}}$,

where $d_{\mathrm{c}, \mathrm{e}}$, and $d_{\mathrm{c}, \mathrm{t}}$ are the experimental and the theoretical densities of the composites respectively, and $\varepsilon$ is the void fraction in the composite.

Experimental densities of the composites were found to be slightly lower than the theoretical density of pure PP as seen in Table 1 except for the wt $\%$ samples. The results indicate that the experimental and the theoretical densities did not show a systematic agreement with the increasing zeolite content, which is again due to the non-uniformity of the zeolite distribution along the PP phase. The theoretical density values were also calculated using the experimental density

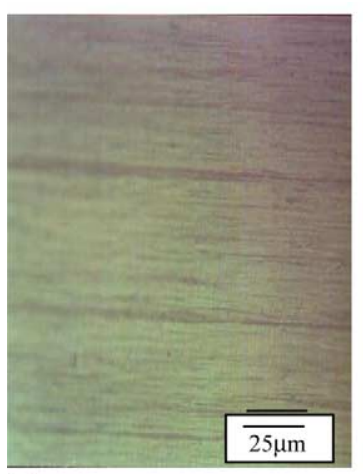

(a)

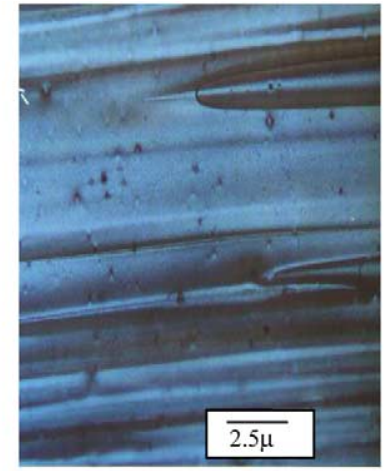

(b)

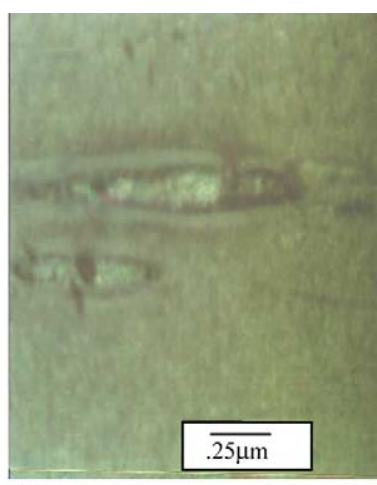

(c)

Fig. 1. Transmitted optical micrographs of 100 times magnified: (a) the tensile tested pure polypropylene film; (b) $6 \mathrm{wt} \%$ zeolite loaded PP composite films; (c) tensile tested $6 \mathrm{wt} \%$ zeolite, loaded PP composite films. 
Table 1

Density of the untreated and treated zeolite filled PP composite films

\begin{tabular}{|c|c|c|c|c|c|c|c|}
\hline $\begin{array}{l}\text { wt } \% \\
\text { Zeolite }\end{array}$ & $\begin{array}{l}\text { Amount of } \\
\mathrm{Ag}^{+} \text {exchanged } \\
\text { on composite }(\mathrm{mg} / \mathrm{g})\end{array}$ & $\begin{array}{l}\text { DOP } \\
(\mathrm{w} / \mathrm{w} \%)\end{array}$ & $\begin{array}{l}\text { Thickness } \\
(\mathrm{mm})\end{array}$ & $\begin{array}{l}\text { Theoretical } \\
\text { density, } \\
d_{\mathrm{c}, \mathrm{t}}\left(\mathrm{g} / \mathrm{cm}^{3}\right)\end{array}$ & $\begin{array}{l}\text { Experimental } \\
\text { density, } \\
d_{\mathrm{c}, \mathrm{e}}\left(\mathrm{g} / \mathrm{cm}^{3}\right) \\
\end{array}$ & $\begin{array}{l}\text { Experimental density } \\
\text { of tensile tested } \\
\text { films }\left(\mathrm{g} / \mathrm{cm}^{3}\right)\end{array}$ & $\begin{array}{l}\text { Void fraction } \\
(\varepsilon)\end{array}$ \\
\hline 0 & 0 & 0 & 0.270 & 0.890 & 0.857 & 0.760 & 0.036 \\
\hline 0 & 0 & 10 & 0.233 & 0.890 & 0.875 & 0.781 & 0.016 \\
\hline 2 & 0 & 10 & 0.266 & 0.899 & 0.871 & 0.662 & 0.031 \\
\hline 4 & 0 & 10 & 0.263 & 0.908 & 0.830 & 0.877 & 0.085 \\
\hline 6 & 0 & 10 & 0.276 & 0.917 & 0.966 & 0.584 & - \\
\hline 2 & 4.36 & 10 & 0.263 & 0.899 & 0.763 & 0.782 & 0.150 \\
\hline 4 & 4.36 & 10 & 0.283 & 0.908 & 0.856 & 0.691 & 0.057 \\
\hline 6 & 4.36 & 10 & 0.306 & 0.917 & 0.947 & - & - \\
\hline 2 & 27.85 & 10 & 0.260 & 0.899 & 0.829 & 0.712 & 0.077 \\
\hline 4 & 27.85 & 10 & 0.253 & 0.908 & 0.874 & 0.625 & 0.037 \\
\hline 6 & 27.85 & 10 & 0.333 & 0.917 & 0.748 & - & 0.184 \\
\hline 2 & 183.78 & 10 & 0.263 & 0.899 & 0.823 & 0.687 & 0.084 \\
\hline 4 & 183.78 & 10 & 0.276 & 0.908 & 0.849 & 0.638 & 0.064 \\
\hline 6 & 183.78 & 10 & 0.320 & 0.917 & 0.919 & - & - \\
\hline
\end{tabular}

and crystallinity data. The relationship for a semicrystalline polymer as:

$\rho_{\mathrm{PP}}=\rho_{\text {amorp }}(1$-crystallinity $)+\rho_{\text {crystal }} *$ crystallinity.

For isotactic PP, $\rho_{\mathrm{A}}=0.85$ and $\rho_{\mathrm{c}}=0.936$ were taken [16]. The crystallinity values were determined using DSC. The detail explanation related to the determination of crystallinity can be found in Section 3.6.1 and the values were given in Table 4. It was observed that the lower density values were obtained compared to the expected ones which again shows the void formation in the composites. The void fractions were in the range of $0.02-0.18$ and were very close to the ones found by Özmıhçı et al. [6].

\subsection{Mechanical properties}

The mechanical properties of the extruded films were given in Table 2. The results of the mechanical tests show that the addition of DOP decreases the yield stress, however, increases the stress at break and elongation at break values. Fig. 2 illustrates the effect of silver concentration on the Young modulus values of the PP-silver exchanged zeolite composites as a function of zeolite loading. A decrease in Young's modulus of PP-zeolite composites with an increase in zeolite loading was observed. The decrease in modulus of PP composites indicates the formation of voids around filler due to poor bonding between the zeolite particles and PP matrix. The Young modulus slightly decreases with the increasing silver concentration. Considering the variation of Young modulus values between 1100 and $1300 \mathrm{MPa}$, it is concluded that silver concentration does not quite affect the Young modulus values of the composites.

A decrease was also observed in the yield stress values with the increasing silver concentration as the zeolite loading increased especially for $6 \mathrm{wt} \%$ zeolite loaded composites as seen in Table 2 . The elongation at break for $6 \mathrm{wt} \%$ zeolite containing film were lower than that of control $(410.6 \%)$ films, and 2 and $4 \mathrm{wt} \%$ zeolite loaded composite films. The low elongation at break values indicated the presence of the brittle fracture of the films.

Table 2

Tensile test results of the PP-zeolite composite films

\begin{tabular}{|c|c|c|c|c|c|c|}
\hline $\begin{array}{l}\text { Zeolite } \\
(\mathrm{wt} \%)\end{array}$ & $\begin{array}{l}\text { DOP \% } \\
(\mathrm{v} / \mathrm{w})\end{array}$ & $\begin{array}{l}\mathrm{Ag}^{+} \text {conc. } \\
(\mathrm{mg} / \mathrm{g} \text { zeolite })\end{array}$ & $\begin{array}{l}\text { Yield stress } \\
(\mathrm{MPa})\end{array}$ & $\begin{array}{l}\text { Stress at break } \\
(\mathrm{MPa})\end{array}$ & $\begin{array}{l}\text { Elongation at } \\
\text { break }(\%)\end{array}$ & $\begin{array}{l}\text { Modulus } \\
(\mathrm{MPa})\end{array}$ \\
\hline $0(\mathrm{PP})$ & 0 & 0 & 24.6 & 29.2 & 389 & 1608 \\
\hline $0(\mathrm{PP})$ & 10 & 0 & 23.6 & 31.3 & 411 & 1316 \\
\hline 2 & 10 & 0 & 20.8 & 31.3 & 424 & 868 \\
\hline 4 & 10 & 0 & 27.9 & 18.8 & 188 & 1274 \\
\hline 6 & 10 & 0 & 27.6 & 24.1 & 320 & 1483 \\
\hline 2 & 10 & 4.36 & 22.3 & 29.5 & 404 & 1058 \\
\hline 4 & 10 & 4.36 & 21.9 & 21.8 & 382 & 1259 \\
\hline 6 & 10 & 4.36 & 15.1 & 15.4 & 7 & 1189 \\
\hline 2 & 10 & 27.85 & 27.2 & 24.4 & 343 & 1323 \\
\hline 4 & 10 & 27.85 & 23.2 & 17.7 & 345 & 1233 \\
\hline 6 & 10 & 27.85 & 14.3 & 15.8 & 6 & 1190 \\
\hline 2 & 10 & 183.78 & 29.5 & 26.5 & 400 & 1288 \\
\hline 4 & 10 & 183.78 & 22.8 & 15.7 & 206 & 1269 \\
\hline 6 & 10 & 183.78 & 12.8 & 13.3 & 5 & 1129 \\
\hline
\end{tabular}




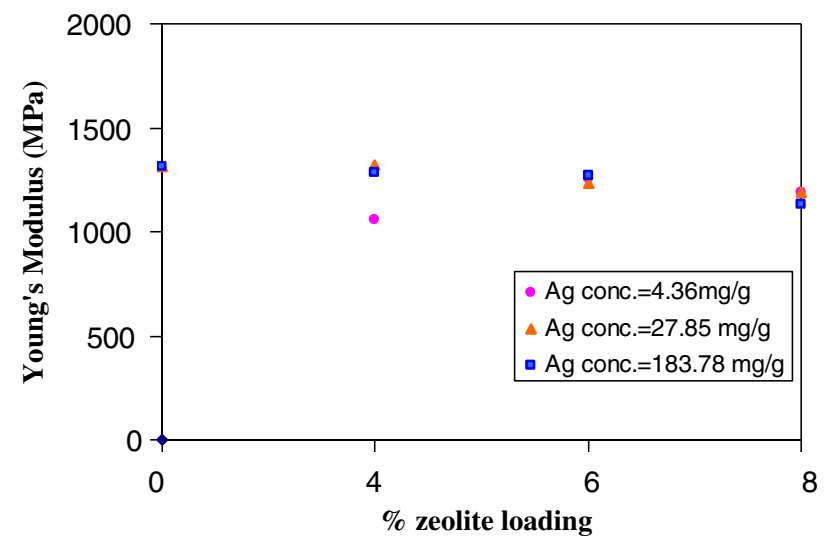

Fig. 2. The effect of zeolite loading and silver concentration on the Young's modulus of the composites.

Interfacial interaction between the polymer matrix and the filler is an important factor affecting the mechanical properties of the composites. Thus, theoretical yield strength and ultimate tensile strength of the composites are modelled to show the effect of interfacial interaction on the tensile strength of the composites. Pukanszky model describes the effects of composition and the interfacial interaction on tensile yield stress or tensile strength of particulate filled polymers is given in Eq. (4). The parameter $B$ is an interaction parameter that is related to the macroscopic characteristics of the filler-matrix interface and interphase [17]

$\sigma_{\mathrm{yc}} / \sigma_{\mathrm{ym}}=\frac{1-\Phi_{\mathrm{f}}}{1+2.5 \Phi_{\mathrm{f}}} \exp \left(B_{\sigma y} \Phi_{\mathrm{f}}\right)$,

Where $\Phi_{\mathrm{f}}$ is the volume fraction of the filler, $\sigma_{\mathrm{yc}}$ and $\sigma_{\mathrm{ym}}$ denote the tensile yield stress or tensile strength of composite and matrix, respectively. The first term in Eq. (4) is related to the decrease in effective load bearing crosssection, while the second one is concerned with the interfacial interaction between filler and matrix. Fig. 3 shows the comparison of the experimental tensile strength data with the Pukanszky model for PP-zeolite composites containing pure zeolite and silver exchanged zeolites, respectively. As seen in the figures, the model does not well predict the data of PP-zeolite composites very well. $B$ parameter in the model characterizes the interaction between PP and zeolite, and the higher the $B$ values indicate the better interaction. Results of the model prediction gave the negative $B$ values which indicated the poor adhesion in PP-zeolite composite system. As the silver concentration were increased, the $B$ values were even more decreased which again showed the worse interfacial adhesion.

\subsection{Discoloration tests}

The discoloration parameters consist of three measures which are $L, a$ and $b$ values. $L$ changes between 0 and 100 , designating the color transition from black

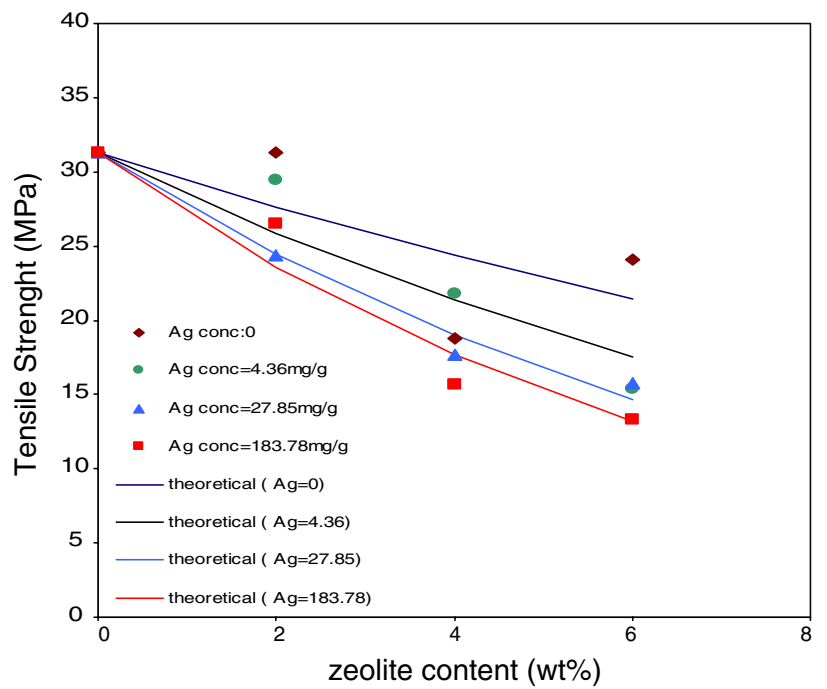

Fig. 3. The effect of zeolite loading and silver concentration on the tensile strength of PP composites.

to white. The $a$ and $b$ values show the transition between green to red and blue to yellow, respectively. The discoloration parameters of the samples were measured using Minolta Colorometer and the results given in Table 3 show the difference according to the reference sample. The reference sample taken as the pure PP film free of both silver and zeolite.

As the silver concentration is increased, the discoloration parameters of the samples change from white to black, red to green and blue to yellow for $L, a$, and, $b$ values respectively. " $L$ " and " $b$ " parameters changed more compared to the " $a$ " values with increasing silver concentration. Fig. 4 shows the change of $L$ parameter according to the control sample $(\Delta L)$ as a function of zeolite loading at three different silver concentrations. As seen in Fig. 4, the higher the silver concentration, the more pronounced discoloring effect was obtained. This effect was also seen by Niira et al. [11]. It can be said that the composites containing $2-6 \mathrm{wt} \%$ zeolites treated with $4.36 \mathrm{mg} \mathrm{Ag}^{+} / \mathrm{g}$ zeolite show the less discoloring effect compared to the control sample.

Table 3

Discoloration test results of PP-silver zeolite composite films

\begin{tabular}{lcccc}
\hline $\begin{array}{l}\text { Zeolite } \\
(\mathrm{wt} \%)\end{array}$ & $\begin{array}{l}\mathrm{Ag}^{+} \text {conc. } \\
(\mathrm{mg} / \mathrm{g} \text { zeolite })\end{array}$ & $\Delta L$ & $\Delta a$ & $\Delta b$ \\
\hline 2 & 4.36 & -1.19 & -0.41 & 1.81 \\
4 & 4.36 & -2.02 & -0.57 & -2.65 \\
6 & 4.36 & -3.71 & -0.63 & 3.96 \\
2 & 27.85 & -2.67 & -1.19 & 6.72 \\
4 & 27.85 & -5.16 & -2.16 & 14.5 \\
6 & 27.85 & -9.93 & -2.50 & 25.3 \\
2 & 183.78 & -6.39 & -0.82 & 12.6 \\
4 & 183.78 & -10.8 & -1.60 & 23.6 \\
6 & 183.78 & -16.3 & -1.34 & 28.8 \\
\hline
\end{tabular}




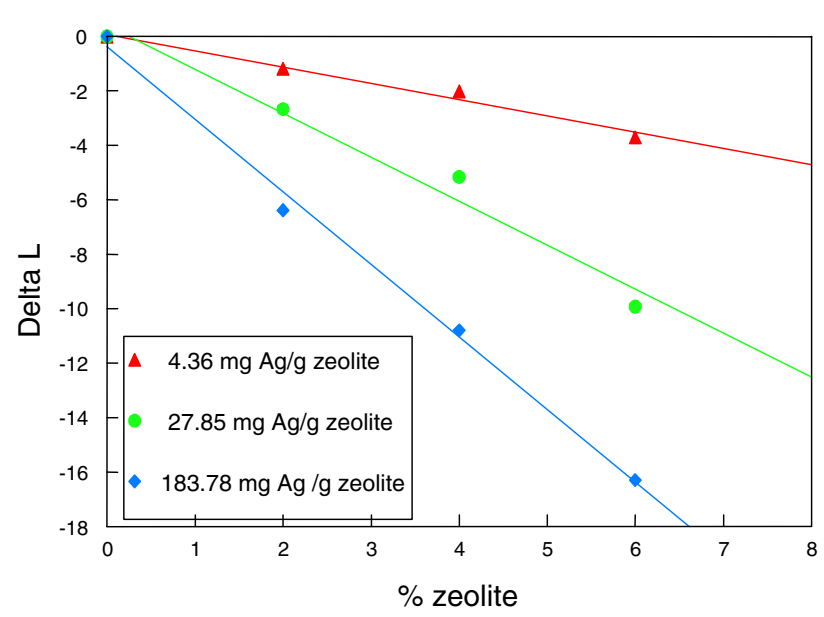

Fig. 4. Discoloring effect of zeolite and $\mathrm{Ag}^{+}$concentration.

\subsection{Thermal characterization studies}

\subsubsection{DSC analyses}

In this study, DSC and TGA were used for the thermal characterizations of the PP, natural zeolite, and PP-silver zeolite composite films. The melting, crystallization, and degradation behaviors, and the kinetic analysis of the composites were investigated. At a heating rate of $10^{\circ} \mathrm{C} / \mathrm{min}$, the quantitative information about peak temperatures for melting and degradation, entalphy of fusion $\left(\Delta H_{\mathrm{f}}\right)$ and entalphy of degradation values $\left(\Delta H_{\mathrm{d}}\right)$, and the $\%$ crystallinity values are tabulated in Table 4.

As seen in Table 4, the melting and degradation peak temperatures of the composites containing $0-6 \mathrm{wt} \%$ zeolite with three different silver concentrations: $4.36,27.85$, $183,78 \mathrm{mg} \mathrm{Ag}^{+} / \mathrm{g}$ zeolite were found to be in the range of $161-165$ and $459-466^{\circ} \mathrm{C}$, respectively. This shows that silver concentration and zeolite loading do not affect the peak temperatures of melting and degradation significantly. Heat of fusion $\left(\Delta H_{\mathrm{f}}\right)$ and heat of degradation
$\left(\Delta H_{\mathrm{d}}\right)$ were determined from the melting and degradation endotherm areas, respectively. Heat of fusion and heat of degradation values showed an increasing trend with increasing zeolite loading and silver concentration except for the case of samples with $183.78 \mathrm{mg} \mathrm{Ag}^{+} / \mathrm{g}$ zeolite. $\Delta H_{\mathrm{f}}$ values were found in the range of 59.6 $84 \mathrm{~kJ} / \mathrm{kg}$ for the $0-6 \%$ weight silver zeolite containing composites. Özmıhçı et al. [6] previously found the $\Delta H_{\mathrm{f}}$ values in the range of $63.8-87 \mathrm{~kJ} / \mathrm{kg}$ for the $0-6 \mathrm{wt} \%$ untreated zeolite containing composites.

The $\%$ crystallinity of the films was determined using the following equation:

$\%$ crystallinity

$$
=\frac{\text { Heat of fusion of the sample }}{\text { Heat of fusion of the } 100 \% \text { crystalline sample }} \times 100 \text {. }
$$

The $\Delta H_{\mathrm{f}}$ value for $100 \%$ crystalline isotactic PP is cited in the literature as $209 \mathrm{~kJ} / \mathrm{kg}$ [18]. This value was used to determine the $\%$ crystallinity of the composites. The higher the zeolite content, the higher the crystallinity values were obtained for the composites. As shown in Table 5, Pure PP and PP-DOP films were $28.5 \%$ and $35 \%$ crystalline, respectively, whereas the crystallinity of the composites was increased with the increasing zeolite content up to $40 \%$. It is concluded that zeolite acts as a nucleating agent in the PP matrix. The degree of crystallinity values of the PP-DOP, $2 \mathrm{wt} \%$ pure zeolite (PP-DOP-\% $\% 2$ zeolite) and silver exchanged zeolite (PPDOP_\% 2 Ag zeolite) loaded PP composite films were also calculated using XRD data as explained in Section 2.4 and shown in Fig. 5. The crystallinity values of PPDOP, $2 \mathrm{wt} \%$ pure zeolite and $2 \mathrm{wt} \%$ silver exchanged zeolite (4.31 mg Ag/gm zeolite) loaded composite films were obtained as $38 \%, 31 \%$ and $33 \%$, respectively. These results were in good agreement with DSC results given in Table 4.

The thermal degradation activation energy of the composites was determined from the DSC curves using Kissinger and Ozawa methods $[19,20]$. According to

Table 4

DSC analysis results of composites

\begin{tabular}{|c|c|c|c|c|c|c|}
\hline $\begin{array}{l}\text { Zeolite loading } \\
(\mathrm{wt} \%)\end{array}$ & $\begin{array}{l}\mathrm{Ag}^{+} \text {conc. } \\
(\mathrm{mg} / \mathrm{g} \text { zeolite })\end{array}$ & $\begin{array}{l}\text { Melting peak } \\
\text { temperature }\left({ }^{\circ} \mathrm{C}\right)\end{array}$ & $\begin{array}{l}\text { Degradation peak } \\
\text { temperature }\left({ }^{\circ} \mathrm{C}\right)\end{array}$ & $\Delta H_{\mathrm{f}}(\mathrm{kJ} / \mathrm{kg})$ & $\Delta H_{\mathrm{d}}(\mathrm{kJ} / \mathrm{kg})$ & $\%$ Crystallinity \\
\hline 0 & 0 & 165.0 & 459.9 & 59.6 & 258.2 & 28.5 \\
\hline 2 & 0 & 163.4 & 460.5 & 67.8 & 346.7 & 32.4 \\
\hline 4 & 0 & 160.6 & 464.1 & 70.3 & 373.4 & 34.0 \\
\hline 2 & 4.36 & 161.0 & 464.2 & 58.4 & 321.0 & 27.9 \\
\hline 4 & 4.36 & 161.5 & 459.9 & 70.0 & 352.1 & 33.5 \\
\hline 6 & 4.36 & 165.6 & 459.3 & 79.2 & 363.6 & 37.9 \\
\hline 2 & 27.85 & 158.4 & 464.1 & 72.7 & 315.9 & 34.8 \\
\hline 4 & 27.85 & 162.7 & 462.8 & 79.3 & 360.5 & 37.9 \\
\hline 6 & 27.85 & 165.7 & 465.7 & 83.8 & 319.4 & 40.1 \\
\hline 2 & 183.78 & 162.7 & 466.5 & 78.2 & 390.2 & 37.4 \\
\hline 4 & 183.78 & 162.7 & 459.9 & 69.7 & 335.3 & 33.3 \\
\hline 6 & 183.78 & 162.6 & 462.6 & 81.5 & 314.6 & 39.0 \\
\hline
\end{tabular}

( $\Delta H_{\mathrm{f}}$ : heat of fusion; $\Delta H_{\mathrm{d}}$ : heat of degradation). 
Table 5

Degradation kinetic constants of the composite films obtained from DSC and TGA

\begin{tabular}{|c|c|c|c|c|c|c|c|c|}
\hline \multirow[t]{2}{*}{$\mathrm{Ag}^{+}$conc. $(\mathrm{mg} / \mathrm{g})$} & \multirow[t]{2}{*}{ Zeolite (\%) } & \multicolumn{3}{|l|}{ DSC } & \multicolumn{4}{|l|}{ TGA } \\
\hline & & $\overline{E(\mathrm{~kJ} / \mathrm{mol})}$ & Frequency factor & $k\left(\min ^{-1}\right)$ at $450^{\circ} \mathrm{C}$ & $E(\mathrm{~kJ} / \mathrm{mol})$ & $L$ & $A$ & $k\left(\min ^{-1}\right)$ at $450^{\circ} \mathrm{C}$ \\
\hline 0 & 0 & 181.1 & $3.5 \times 10^{12}$ & 0.285 & 56.1 & 5 & $4.79 \times 10^{3}$ & 0.42 \\
\hline 4.36 & 4 & 168 & $4.09 \times 10^{11}$ & 0.297 & 96.5 & 5 & $9.98 \times 10^{6}$ & 1.06 \\
\hline 27.85 & 4 & 226 & $6.2 \times 10^{15}$ & 0.291 & 56.5 & 4 & $7.75 \times 10^{3}$ & 0.64 \\
\hline 183.78 & 4 & 214 & $8.68 \times 10^{14}$ & 0.299 & 64.6 & 5 & $2.78 \times 10^{4}$ & 0.59 \\
\hline
\end{tabular}

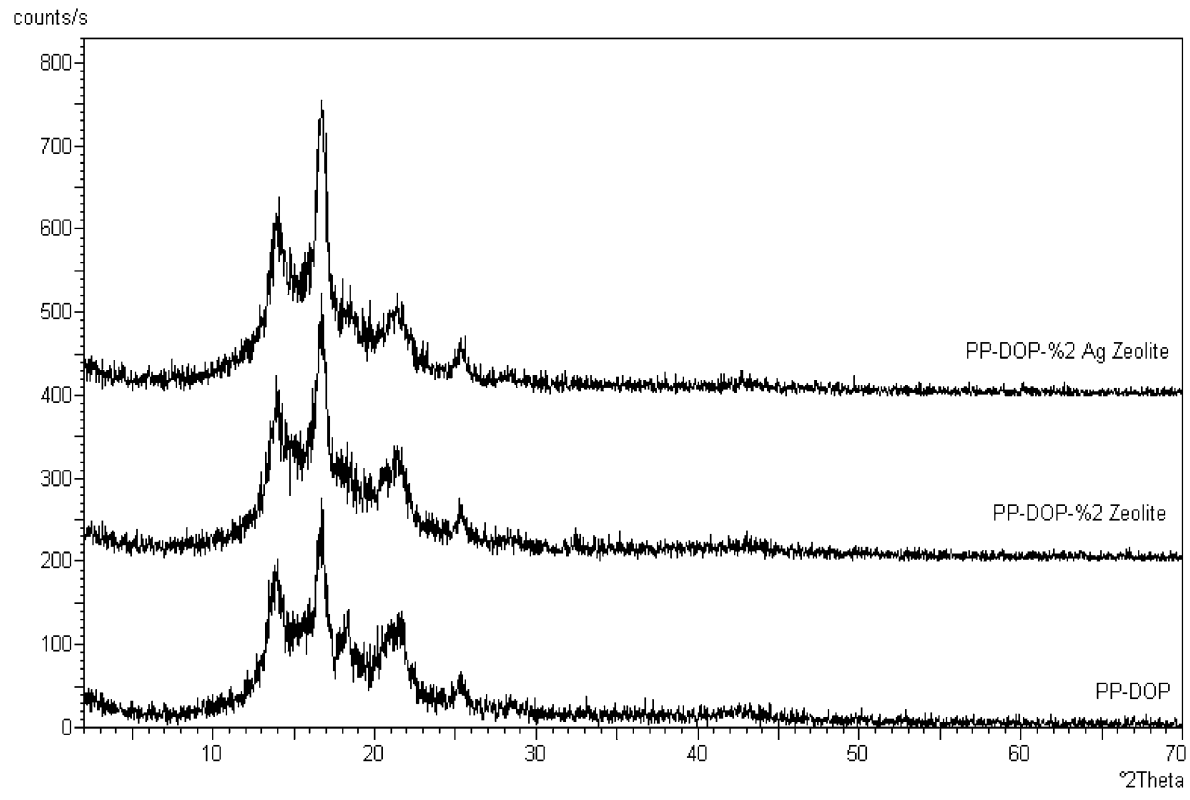

Fig. 5. X-ray diffraction patterns of PP-DOP, $2 \mathrm{wt} \%$ zeolite and $2 \mathrm{wt} \%$ silver exchanged zeolite loaded composite films.

the Kissinger method, the activation energy of the composites for the decomposition reaction is determined from the slope of the logarithmic heating rate $(\ln \beta)$ against $1 / T$ plot corresponding to $-E_{\mathrm{a}} / R$ :

$\frac{\mathrm{d}(\log \beta)}{\mathrm{d}(1 / T)}=-\frac{E_{\mathrm{a}}}{R}$,

where $\beta$ is the heating rate $\left({ }^{\circ} \mathrm{C} / \mathrm{min}\right), T$ is the peak maximum for degradation temperature, $E_{\mathrm{a}}$ is the activation energy, and $R$ is the gas constant. The thermal decomposition temperature was measured from the DSC thermograms of the composites for various heating rates. The DSC thermograms of the $4 \mathrm{wt} \%$ zeolite loaded with $4.36 \mathrm{mg} / \mathrm{g}$ silver performed at three different heating rates are given in Fig. 6. Fig. 7 illustrates the plot of $\ln \beta$ vs. $1 / T_{\mathrm{d}}$ for the same composites. From the slope of this plot, thermal decomposition activation energy, $E_{\mathrm{a}}$, was calculated as $170 \mathrm{~kJ} / \mathrm{mol}$.

DSC curves were also analyzed according to the Ozawa method using the kinetic analysis software of Shimadzu 50. The quantitative information obtained from the kinetic analysis of the samples performed with both the Ozawa and the Kissinger methods were tabulated in Table 5. As seen from the table, the activation energies obtained by the two methods were in good agreement with each other.

Since the thermal decomposition occurs around $450{ }^{\circ} \mathrm{C}$, the reaction constant $k$ was calculated at $450{ }^{\circ} \mathrm{C}$ using the Arrhenius equation:

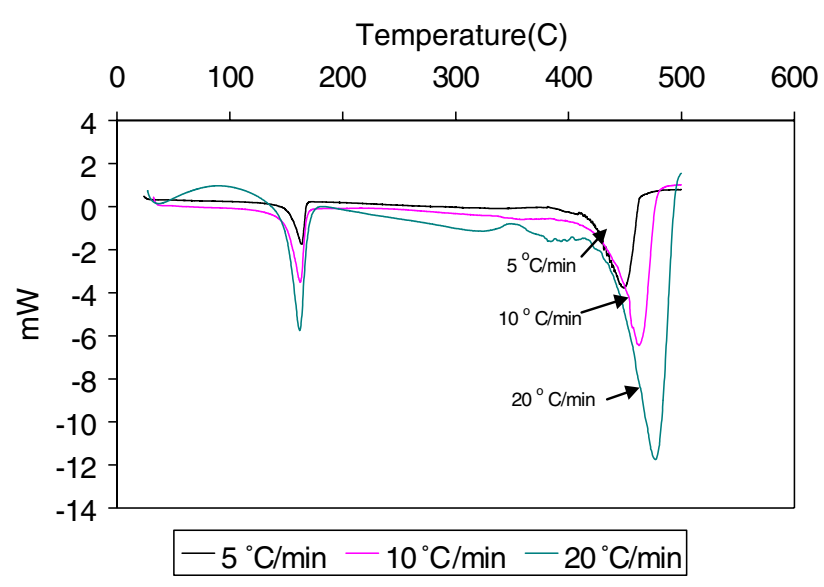

Fig. 6. DSC curves of $4 \mathrm{wt} \%$ zeolite composites with $4.36 \mathrm{mg} \mathrm{Ag}^{+} / \mathrm{g}$ zeolite at three different heating rates. 


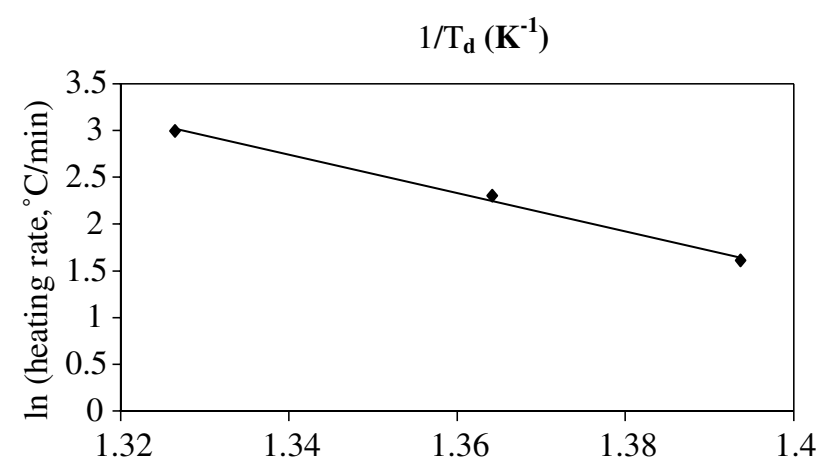

Fig. 7. Kissinger plot of $4 \mathrm{wt} \%$ zeolite composite film treated with $4.36 \mathrm{mg} \mathrm{Ag} / \mathrm{g}$ zeolite.

$k=A \exp \left(-\frac{E}{R T}\right)$,

where $E$ is the activation energy $(\mathrm{kJ} / \mathrm{mol}), A$ is the frequency factor $\left(\mathrm{min}^{-1}\right), R$ is the gas constant, and $T$ is the temperature $(\mathrm{K})$.

It was observed that the reaction constant was not significantly affected by the increasing silver concentration, and that slight increases occurred, but zeolite addition decreased the decomposition rate.

\subsubsection{TGA analyses}

Composite films were all analyzed using TGA with a heating rate of $10^{\circ} \mathrm{C} / \mathrm{min}$. The TGA analyses of the three different samples showed very similar results. With the increasing silver concentration, the onset of degradation shifts slightly to higher values. On the average, the degradation started at around $220^{\circ} \mathrm{C}$, and terminated at about $550^{\circ} \mathrm{C}$. The TGA curves of the samples containing 27.85 and $183.78 \mathrm{mg} / \mathrm{g}$ silver almost overlapped each other, while the sample containing $4.36 \mathrm{mg} / \mathrm{g}$ silver showed a slower decrease compared to the other two samples. The weight losses of the $4.36,27.85$, and $183.78 \mathrm{mg} / \mathrm{g}$ silver containing samples at $550{ }^{\circ} \mathrm{C}$ came out to be $98.6 \%, 98.2 \%$, and $96.9 \%$, respectively. Although all the samples were supposed to contain $4 \mathrm{wt} \%$ zeolite, the TGA results indicated that the zeolite distribution along the composite films was not uniform.

The kinetic analysis was performed with heating rates of 5,10 , and $20^{\circ} \mathrm{C} / \mathrm{min}$ for the $4 \mathrm{wt} \%$ zeolite samples. Fig. 8 shows the TGA curves of the $4 \mathrm{wt} \%$ zeolite samples containing $27.85 \mathrm{mg} / \mathrm{g}$ silver. As the heating rates increased, the thermograms shifted toward the right and the degradation temperature increased. Kinetic analyses of these composites were performed using Shimadzu 51 TGA kinetic analysis software within a temperature range of $250-550{ }^{\circ} \mathrm{C}$. The Ozawa plot shows the logarithm of heating rate versus $1 / T$ at constant $x$ values (reaction percent) for different conversions (weight losses). From the slope of the lines, the activation energy, $E_{\mathrm{a}}$, is calculated for different weight losses

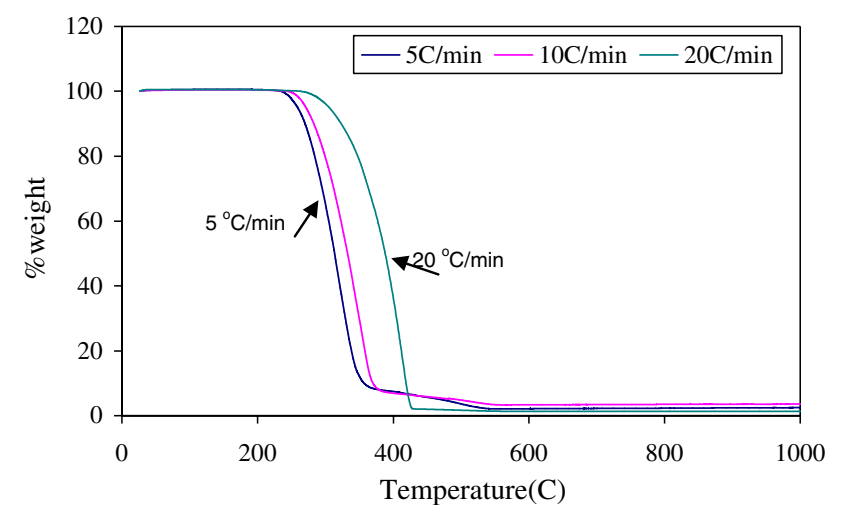

Fig. 8. TGA curves of the $4 \mathrm{wt} \%$ silver zeolite $\left(27.85 \mathrm{mg} \mathrm{Ag}^{+} / \mathrm{g}\right.$ zeolite) loaded composites.

and averaged by the software. The kinetic energies and the related parameters obtained for the $4 \mathrm{wt} \%$ zeolite containing samples are shown in Table 5. $A$ is the frequency factor and $L$ is the order for degradation reaction. $L$ is a measure of minimum degree of polymerization of volatile degradation products. If the degree of polymerization of degraded polymer is lower than a critical $L$ value, it is volatile. $L$ was around 5 for PP [6].

Reaction rate constant for the degradation reaction was determined using Arrhenius equation at $450{ }^{\circ} \mathrm{C}$ and given in Table 5. It was observed that the zeolite addition into the PP matrix speeds down the decomposition reaction, however activation energies of the samples with a specified zeolite loading decreased with the increasing silver concentration. This showed that PP is much more susceptible to thermal decomposition in the presence of silver exchanged zeolite compared to the pure PP. The $k$ values also determined at $250{ }^{\circ} \mathrm{C}$ in this study were close to the ones found by Özmıhçı et al. [6] for the films prepared by the same material but with a different extruder operating at $260{ }^{\circ} \mathrm{C}$.

The $E_{\text {a }}$ and $A$ values found for degradation of PP by DSC and TGA were very different from each other indicating heat absorbed and evolved gaseous were not proportional.

\section{Conclusions}

In the present study, the silver exchanged natural zeolite-PP composites were prepared via extrusion technique, and the effects of zeolite loading and silver concentration were investigated on the thermal, mechanical, and structural properties of the composite films. The thermal characterization studies showed that the addition of the zeolite increased the crystallinity of the structure acting as a nucleating agent in the PP crystallization as well as retarding the degradation temperature of PP. It was found that at low silver concentrations, the zeolite 
behaved as a decelerating agent in PP degradation, however at higher silver concentrations, the composites degraded at a faster rate than pure PP. As a result, PP is much more susceptible to the thermal decomposition in the presence of silver exchanged zeolite compared to the pure zeolite. This was also indicated by the discoloring and brittle fracture of the films at high $\mathrm{Ag}^{+}$and zeolite concentration. It was also found that the addition of the zeolite into the PP matrix decreased the density of pure PP $\left(0.89 \mathrm{~g} / \mathrm{cm}^{3}\right)$ indicating the formation of voids confirming previous studies.

The optimum conditions obtained in this study for the silver zeolite-PP film production are $2-4 \mathrm{wt} \%$ zeolite treated with $4.36 \mathrm{mg} \mathrm{Ag}^{+} / \mathrm{g}$ zeolite concentration. At higher zeolite loading, the film becomes brittle, and at higher Ag concentration the produced films were discolored. Since polypropylene having silver exchanged zeolite in an extruder causes thermal degradation, the treatment of $\mathrm{PP}$-zeolite composite films with silver containing solution would be a better alternative for antimicrobial film preparation.

\section{Acknowledgments}

The authors express their thanks to Petkim Petrochemicals Company for the supply of PP. This research was funded by Technical and Scientific Research Council of Turkey (TÜBİTAK) and Government Planning Institute (DPT) Grant numbers MISAG 129 and $120290 \mathrm{~K}$, respectively.

\section{References}

[1] Ghosh K, Maiti SN. Melt rheological properties of silver powder filled polypropylene composites. Polym Plastic Technol Eng 1997;35(5):700-22.

[2] Nago S, Mizutani Y. Preparation of microporous polypropylene sheets containing $\mathrm{CaCO}_{3}$ filler: effect of draft ratio. J Appl Polym Sci 1996;61:31-5.
[3] Leong YW, Ishak MZA, Ariffin A. Mechanical and thermal properties of talc and calcium carbonate filled hybrid composites. J Appl Polym Sci 2004;91(5):3327-36.

[4] Demjen Z, Pukanzky B, Nagy J. Evaluation of interfacial interaction in polypropylene/surface treated $\mathrm{CaCO}_{3}$ composites. Composites A 1998:323-9.

[5] Acosta JL, Morales E, Ojeda MC, Linares A. The effect of interfacial adhesion and morphology on the mechanical properties of polypropylene composites containing different acid surface treated sepiolites. J Mater Sci 1986;21:725-8.

[6] Özmıhcı F, Balköse D, Ülkü S. Natural zeolite polypropylene composite film preparation and characterization. J Appl Polym Sci 2001;82:2913-21.

[7] Hagiwara Z, Hoshiro S, Nohara S, Tagawa K. Zeolite particles retaining silver ions having antibacterial properties. United States Patent 4,911,898; 1990.

[8] Kawahara K, Tsuruda K, Morishita M, Uchida M. Antibacterial effect of silver-zeolite on oral bacteria under anaerobic conditions. Dental Mater 2000;16:452-5.

[9] Klasen HJ. A historical review of the use of silver in the treatment of burns. II: renewed interest for silver. Burns 2000:26.

[10] Czaran E, Papp J, Agnes MK, Domokos E. Ag-ion exchange by natural mordenite and clinoptilolite. Acta Chim Hungarica 1989;126(5).

[11] Niira R, Niira Y, Yamamato T, Uchida M. Antibiotic zeolite. United States Patent 4,938,955; 1990.

[12] Akovalı G, Akman MA. Mechanical properties of plasma surface-modified calcium carbonate - polypropylene composites. Polym Int 1997;42:195-202.

[13] Akdeniz Y. Cation exchange in zeolite, structure modification by using microwave. M.S. Thesis, İzmir Institute of Technology, Chemical Engineering Department, İzmir, Turkey; 1999.

[14] Özmıhçı, F. Polypropylene - natural zeolite composite films. M.S. Thesis, Izmir Institute of Technology, Chemical Engineering Department, Izmir, Turkey; 1999.

[15] Pehlivan, H. Preparation and characterization of polypropylene based composite films. M.S. Thesis, Izmir Institute of Technology, Chemical Engineering Department İzmir, Turkey; 2001.

[16] Brandrup J, Immergut EH, Grulke EA. Polymer handbook. 4th ed.. Wiley-Interscience; 1999.

[17] Pukanszky B, Tudos F. The possible mechanisms of polymerfiller interaction in $\mathrm{PP}-\mathrm{CaCO}_{3}$ composites. J Mater Sci Lett 1989;8:1040-2.

[18] Horrocks AR, D'Souza JA. Physicochemical changes in stabilized, oriented polypropylene films during the initial stages of thermal oxidation. J Appl Polym Sci 1991;42:243-61.

[19] Ozawa T. Polymer 1971;12:150.

[20] Kissinger H. Reaction kinetics in differential thermal analysis. Anal Chem 1957;29:1702-6. 